\title{
A new criterion for the alarm point using a combination of waveform amplitude and onset latency in $\operatorname{Br}(\mathrm{E})$-MsEP monitoring in spine surgery
}

\author{
Kazuyoshi Kobayashi, MD, ${ }^{1}$ Kei Ando, MD, ${ }^{1}$ Ryuichi Shinjo, MD, ${ }^{2}$ Kenyu Ito, MD, ${ }^{1}$ \\ Mikito Tsushima, MD, ${ }^{1}$ Masayoshi Morozumi, MD, ${ }^{1}$ Satoshi Tanaka, MD,1 Masaaki Machino, MD,1 \\ Kyotaro Ota, MD, ${ }^{1}$ Naoki Ishiguro, MD, ${ }^{1}$ and Shiro Imagama, MD'
}

${ }^{1}$ Department of Orthopaedic Surgery, Nagoya University Graduate School of Medicine, Showa-ku, Nagoya; and ${ }^{2}$ Department of Orthopaedic Surgery, Anjo Kosei Hospital, Anjo, Aichi, Japan

\begin{abstract}
OBJECTIVE Monitoring of brain evoked muscle-action potentials ( $\mathrm{Br}[\mathrm{E}]-\mathrm{MsEPs}$ ) is a sensitive method that provides accurate periodic assessment of neurological status. However, occasionally this method gives a relatively high rate of false-positives, and thus hinders surgery. The alarm point is often defined based on a particular decrease in amplitude of a $\mathrm{Br}(\mathrm{E})-\mathrm{MsEP}$ waveform, but waveform latency has not been widely examined. The purpose of this study was to evaluate onset latency in $\mathrm{Br}(\mathrm{E})$-MsEP monitoring in spinal surgery and to examine the efficacy of an alarm point using a combination of amplitude and latency.
\end{abstract}

METHODS A single-center, retrospective study was performed in 83 patients who underwent spine surgery using intraoperative $\mathrm{Br}(\mathrm{E})-\mathrm{MsEP}$ monitoring. A total of 1726 muscles in extremities were chosen for monitoring, and acceptable baseline $\mathrm{Br}(\mathrm{E})$-MsEP responses were obtained from 1640 (95\%). Onset latency was defined as the period from stimulation until the waveform was detected. Relationships of postoperative motor deficit with onset latency alone and in combination with a decrease in amplitude of $\geq 70 \%$ from baseline were examined.

RESULTS Nine of the 83 patients had postoperative motor deficits. The delay of onset latency compared to the control waveform differed significantly between patients with and without these deficits $(1.09 \% \pm 0.06 \%$ vs $1.31 \% \pm 0.14 \%, p<$ 0.01). In ROC analysis, an intraoperative $15 \%$ delay in latency from baseline had a sensitivity of $78 \%$ and a specificity of $96 \%$ for prediction of postoperative motor deficit. In further ROC analysis, a combination of a decrease in amplitude of $\geq$ $70 \%$ and delay of onset latency of $\geq 10 \%$ from baseline had sensitivity of $100 \%$, specificity of $93 \%$, a false positive rate of $7 \%$, a false negative rate of $0 \%$, a positive predictive value of $64 \%$, and a negative predictive value of $100 \%$ for this prediction.

CONCLUSIONS In spinal cord monitoring with intraoperative $\mathrm{Br}(\mathrm{E})-\mathrm{MsEP}$, an alarm point using a decrease in amplitude of $\geq 70 \%$ and delay in onset latency of $\geq 10 \%$ from baseline has high specificity that reduces false positive results. https://thejns.org/doi/abs/10.3171/2018.3.SPINE171348

KEYWORDS Br(E)-MsEP; onset latency value; delay latency rate; sensitivity; specificity; false positive; combination; diagnostic technique; surgical technique

I NTRAMEDULLARY tumor resection, ossification of the posterior longitudinal ligament (OPLL) decompression procedures, and scoliosis surgery are often performed in critical situations, ${ }^{1,4,10}$ and the importance of intraoperative spinal cord monitoring in these spinal sur- geries is widely acknowledged. ${ }^{16,20,25,28,32}$ Somatosensory evoked potentials (SSEPs) have been used to monitor spinal surgery since the $1980 \mathrm{~s}, 3,18,26$ and spinal cord evoked potentials (SCEPs) after brain stimulation (Br-SCEP, Dwave) have been used for motor pathway monitoring since

ABBREVIATIONS AIS = adolescent idiopathic scoliosis; $\mathrm{Br}(\mathrm{E})-\mathrm{MsEP}=$ brain evoked muscle-action potential; EMG = electromyography; FNR = false negative rate; FPR = false positive rate; $\mathrm{MIOM}=$ multimodal intraoperative monitoring; $\mathrm{MMT}=$ manual muscle test; NPV = negative predictive value; OLF = ossification of the ligament flavum; OPLL = ossification of the posterior longitudinal ligament; PPV = positive predictive value; SBP = systolic blood pressure; SCEP = spinal cord evoked potential; SSEP = somatosensory evoked potential.

SUBMITTED December 6, 2017. ACCEPTED March 14, 2018.

INCLUDE WHEN CITING Published online July 27, 2018; DOI: 10.3171/2018.3.SPINE171348. 
the 1990s..$^{15,30,31}$ Other monitoring techniques include freerunning electromyography, ${ }^{7,9}$ monitoring of SCEPs after stimulation of the spinal cord (Sp-SCEPs) or peripheral nerve (Pn-SCEPs), and monitoring of brain evoked muscle-action potentials (Br[E]-MsEPs). 2,16,17,19 $\mathrm{Br}(\mathrm{E})-\mathrm{MsEP}$ monitoring is regarded as the most sensitive method ${ }^{17,30}$ for accurate periodical assessment of neurological status, but a few reports have shown that $\mathrm{Br}(\mathrm{E})-\mathrm{MsEP}$ monitoring can produce a relative high rate of false-positives, which can hinder surgery. ${ }^{20,25}$

$\mathrm{Br}(\mathrm{E})-\mathrm{MsEP}$ monitoring is mainly used for intraoperative spinal cord monitoring, and previously the alarm point has been defined as a particular decrease in waveform amplitude. However, the utility of waveform latency has not been widely examined. Thus, we examined the characteristics of latency in $\mathrm{Br}(\mathrm{E})-\mathrm{MsEP}$ monitoring. The purpose of this study is to evaluate onset latency and examine its efficacy for prediction of postoperative motor deficit using a delay in onset latency in combination with an amplitude decrease in $\operatorname{Br}(\mathrm{E})-\mathrm{MsEPs}$. The final goal is to define a new alarm point based on a combination of latency and amplitude.

\section{Methods}

\section{Patient Selection and Neurological Evaluation}

A total of 91 consecutive cervical and thoracic spine surgeries performed under intraoperative neurophysiological monitoring with $\mathrm{Br}(\mathrm{E})$-MsEPs at our hospital were reviewed retrospectively. Eight cases from which no monitorable baseline $\operatorname{Br}(\mathrm{E})$-MsEP from any lower extremity muscle was obtained were excluded from the study. Preoperative motor status itself was not included in the exclusion criteria. Finally, 83 cases with 1726 monitored muscles in the extremities were selected for the study based on acceptable baseline $\operatorname{Br}(\mathrm{E})$-MsEP responses. The patients had a mean age of 45 years (range 10-74 years); 49 were female and 34 were male. The diseases were intradural extramedullary tumor $(n=21)$, OPLL or ossification of the ligament flavum (OLF) $(\mathrm{n}=19)$, adolescent idiopathic scoliosis (AIS) $(\mathrm{n}=18)$, spinal intramedullary tumor $(\mathrm{n}=$ 12), congenital scoliosis $(n=7)$, and others $(n=6)$; and 21 patients had preoperative motor deficits. The McCormick grade at admission was I (normal gait) in 62 cases, II (mild gait disturbance not requiring support) in 10 cases, III (able to walk with support) in 5 cases, IV (assistance required for ambulation) in 5 cases, and $\mathrm{V}$ (wheelchair needed) in 1 case. ${ }^{22}$

The onset latency was defined as the period from stimulation to detection of the waveform (Fig. 1), and the \% latency delay was calculated from the onset latency at baseline: [(latency - latency at baseline)/latency at baseline] $\times 100$. A decrease in postoperative manual muscle test (MMT) score of $\geq 1$ compared with preoperative MMT was defined as a postoperative motor deficit, and relationships with onset latency and with a combination of onset latency and a decrease in amplitude of $\geq 70 \%$ from baseline ${ }^{11,17}$ were examined. This study was approved by the institutional review board of Nagoya University Graduate School of Medicine, and each patient gave informed consent before enrollment.

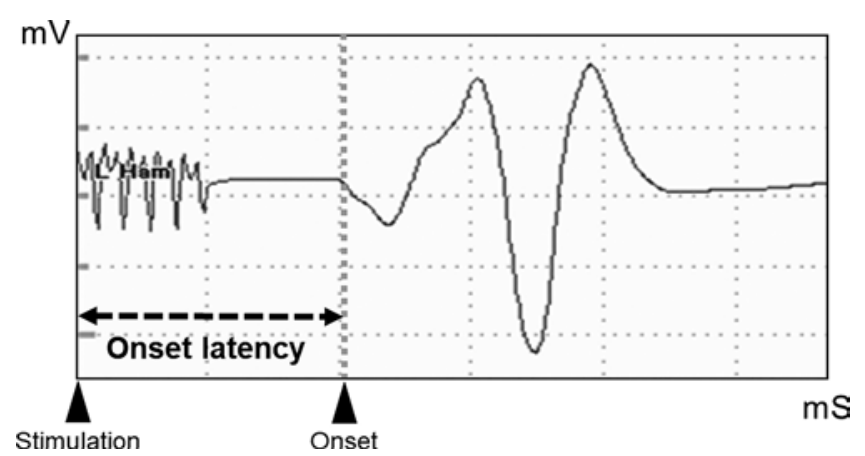

FIG. 1. Onset latency was defined as the period from stimulation until the waveform was detected. $\mathrm{mS}=$ milliseconds.

\section{Anesthetic Management and General Conditions During Surgery}

A minimal benzodiazepine dose was used as preanesthetic medication to avoid possible suppression of waveform latency and amplitude. Propofol (3-4 mg/ $\mathrm{kg}$ ), vecuronium $(0.12-0.16 \mathrm{mg} / \mathrm{kg})$, and fentanyl ( $2 \mathrm{mg} /$ $\mathrm{kg}$ ) were administered for induction, and anesthesia was maintained with propofol $(50-100 \mu \mathrm{g} / \mathrm{kg} / \mathrm{min})$, fentanyl (1-2.5 $\mu \mathrm{g} / \mathrm{kg} / \mathrm{hr}$ ), and vecuronium (0.01-0.04 mg/kg/ $\mathrm{hr}$ ). Anesthesia was given as appropriate with continuous prostaglandin E1 (PGE1) and a short-acting $\beta 1$ blocker (landiolol). Patients were maintained in a normothermic state, and the temperature was raised in the event of possible intraoperative spinal damage. Systolic blood pressure (SBP) variations were measured during surgery, and SBPs were determined at the time of waveform deterioration. ${ }^{11}$

\section{Stimulation and Recording Methods}

An MS120B system (Nihon Kohden) was used to perform transcranial stimulation, with parameters of 5 stimulations in a row at 2-msec intervals, a constant biphasic current of $200 \mathrm{~mA}$ for $500 \mu \mathrm{sec}$, a $50-1000-\mathrm{Hz}$ filter, and a 100-msec epoch time with $\leq 20$ recorded signal responses. The stimulated point was $2 \mathrm{~cm}$ anterior and 6 $\mathrm{cm}$ lateral from the $\mathrm{Cz}$ location over the cerebral cortex motor area. Using the Neuromaster MEE-1232 version 05.10 (Nihon Kohden), which is expandable to 32 channels, muscle action potentials were recorded from the upper and lower extremities via a pair of needle electrodes 3 to $5 \mathrm{Br}(\mathrm{E})$-MsEPs apart. ${ }^{11}$ The target muscles in cervical spine surgery (bilateral trapezius, triceps, deltoid, biceps, brachioradialis, abductor digit minimi, extensor carpi ulnaris, adductor longus, quadriceps femoris, hamstrings, tibialis anterior, gastrocnemius, abductor hallucis, and anal sphincter muscles) were routinely monitored using 28 channels. The target muscles in thoracic spine surgery (bilateral deltoid, extensor carpi ulnaris, adductor longus, quadriceps femoris, hamstrings, tibialis anterior, gastrocnemius, abductor hallucis, and anal sphincter muscles) were routinely monitored using 18 channels. ${ }^{13,14} \mathrm{Br}(\mathrm{E})$ MsEP data from these muscles were used for analysis. Multimodal monitoring was used in all cases, with a particular combination of D-wave and SSEP. Free-running electromyography (EMG) from all muscles was monitored throughout the operation..$^{12,13}$ 
TABLE 1. Details of cases with postoperative neurological deficits $(n=9)$

\begin{tabular}{|c|c|c|c|c|c|c|}
\hline \multirow{2}{*}{$\begin{array}{c}\text { Age } \\
\text { (yrs), } \\
\text { Sex }\end{array}$} & \multirow[b]{2}{*}{ Disease } & \multirow{2}{*}{$\begin{array}{l}\text { Timing of Waveform } \\
\text { Deterioration }\end{array}$} & \multirow[b]{2}{*}{ Deterioration in Latency \& Amp } & \multirow{2}{*}{$\begin{array}{l}\text { Procedures in Response to } \\
\text { Monitoring Change }\end{array}$} & \multicolumn{2}{|c|}{$\begin{array}{c}\text { McCormick } \\
\text { Grade }\end{array}$} \\
\hline & & & & & Preop & Postop \\
\hline $13, \mathrm{~F}$ & Scoliosis & After rotation maneuver & Latency delayed by $23 \%$; amp deter below $70 \%$ & $\begin{array}{l}\text { Maneuver interruption \& release of } \\
\text { correction }\end{array}$ & I & III \\
\hline $47, \mathrm{M}$ & T-OPLL & During decompr & Latency delayed by $13 \%$; amp deter below $70 \%$ & Dekyphotic corr fusion w/ instr & I & IV \\
\hline $33, \mathrm{M}$ & T-OPLL & During decompr & Latency delayed by $55 \%$; amp deter below $80 \%$ & Dekyphotic corr fusion w/ instr & III & IV \\
\hline $52, \mathrm{~F}$ & T-OPLL & During decompr & Latency delayed by $20 \%$; amp deter below $80 \%$ & Dekyphotic corr fusion w/ instr & II & III \\
\hline $49, \mathrm{~F}$ & T-OPLL & After screw insertion & Latency delayed by $11 \%$; amp deter below $70 \%$ & $\begin{array}{l}\text { Alignment maintained using rod \& } \\
\text { decompr quickly }\end{array}$ & III & V \\
\hline $37, \mathrm{M}$ & T-OPLL & After screw insertion & Latency delayed by $41 \%$; amp deter below $70 \%$ & $\begin{array}{l}\text { Alignment maintained using rod \& } \\
\text { decompr quickly }\end{array}$ & II & III \\
\hline $42, \mathrm{M}$ & IM tumor & During tumor excision & Latency delayed by $31 \%$; amp deter below $70 \%$ & Temp susp of proc \& IV steroid admin & II & IV \\
\hline $54, \mathrm{~F}$ & IM tumor & During tumor excision & Latency delayed by $42 \%$; amp deter below $90 \%$ & Temp susp of proc \& IV steroid admin & III & V \\
\hline $48, F$ & IM tumor & During tumor excision & Latency delayed by $49 \%$; amp deter below $80 \%$ & Temp susp of proc \& IV steroid admin & II & IV \\
\hline
\end{tabular}

Admin = administration; amp = amplitude; corr = corrective; decompr = decompression; deter = deteriorated; IM = intramedullary; instr = instrumentation; IV = intravenous; proc $=$ procedure; susp $=$ suspension; temp $=$ temporary; $\mathrm{T}-\mathrm{OPLL}=$ thoracic OPLL.

\section{Monitoring and Alert Parameters}

The $\mathrm{Br}(\mathrm{E})-\mathrm{MsEP}$ baseline was determined immediately after documented surgical exposure of the spine. Waiting until this point for baseline measurements reduced the effects on $\operatorname{Br}(\mathrm{E})$-MsEP responses because of body and spinal cord temperature changes occurring with exposure. Signals were rechecked after surgical exposure, screw insertion, decompression, and wound closure. Surgeons were informed of an acute change in the $\operatorname{Br}(\mathrm{E})$-MsEP response. ${ }^{13,14}$ If a waveform changed during surgery, SBP was raised or hypotensive anesthesia was reversed, the patient was warmed, and irrigation was performed with warm saline. If the waveform did not recover, surgery at the then-current site was suspended. Surgery at a different site continued until the waveform recovered. If there was no improvement, surgery was terminated. ${ }^{12}$

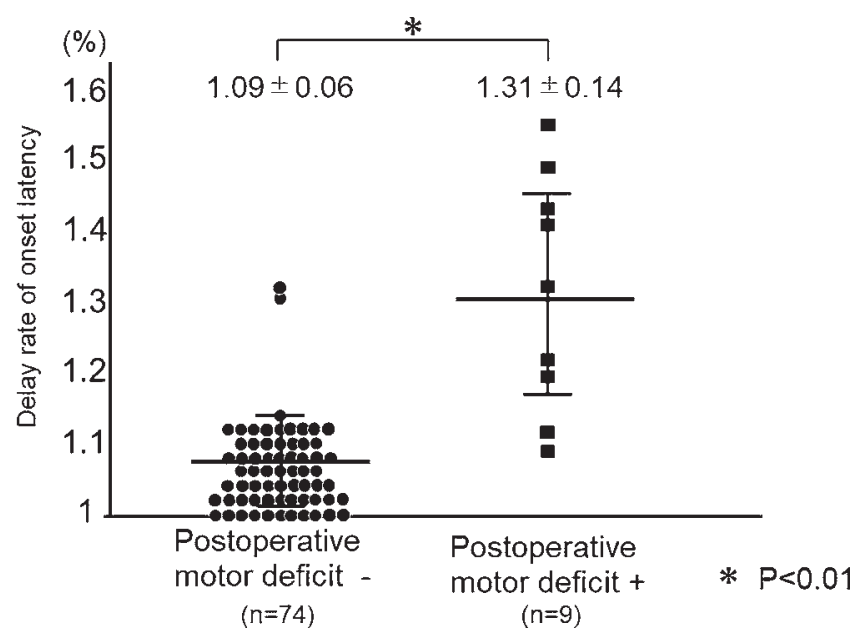

FIG. 2. Change in onset latency compared to the control waveform ( $\%$ delay of the baseline latency) in cases with and without postoperative motor deficit. The mean values for the 2 groups were significantly different $(p<0.01)$.

\section{Results}

Of 1726 muscles used for monitoring in the extremities of 83 patients, acceptable baseline $\mathrm{Br}(\mathrm{E})$-MsEP responses were obtained from 1640 (95\%). Of the 83 patients, 9 (11\%) had postoperative motor deficits, of which $0,0,3,4$, and 2 were classified at discharge into McCormick grades I, II, II, IV, and V, respectively. The details of responses to monitoring and changes in amplitude and latency in these 9 cases are shown in Table 1.

The onset latency compared to the control waveform differed significantly in cases with and without a postoperative motor deficit $(1.09 \% \pm 0.06 \%$ vs $1.31 \% \pm 0.14 \%$, p $<0.01)$ (Fig. 2). In receiver operating characteristic (ROC) analysis, an intraoperative $\mathrm{Br}(\mathrm{E})$-MsEP latency delay of $15 \%$ from baseline had a sensitivity of $78 \%$ and a specificity of $96 \%$ for prediction of postoperative motor deficit (Fig. 3).

A decrease in intraoperative amplitude of $\geq 70 \%$ from baseline occurred in 30 cases, with a sensitivity of $100 \%$,

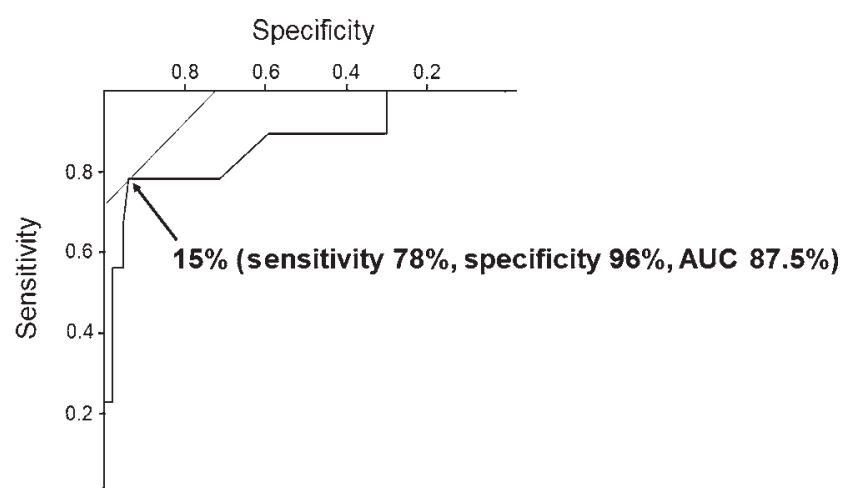

FIG. 3. ROC curve for determination of the cutoff for prediction of postoperative motor deficit using the onset latency of the intraoperative $\mathrm{Br}(\mathrm{E})-\mathrm{MsEP}$ waveform (expressed as \% delay of the baseline latency). $A \cup C=$ area under the ROC curve. 
TABLE 2. Relationship of postoperative motor deficit with waveform deterioration

\begin{tabular}{|c|c|c|c|c|c|c|c|c|c|}
\hline \multirow[b]{2}{*}{ Waveform Deterioration } & \multirow{2}{*}{$\begin{array}{l}\text { All } \\
\text { Pts }\end{array}$} & \multicolumn{2}{|c|}{ Postop Motor Deficit } & \multirow[b]{2}{*}{ Sensitivity } & \multirow[b]{2}{*}{ Specificity } & \multirow[b]{2}{*}{ FPR } & \multirow[b]{2}{*}{ FNR } & \multirow[b]{2}{*}{ PPV } & \multirow[b]{2}{*}{ NPV } \\
\hline & & Present & Absent & & & & & & \\
\hline Decrease in amp of $\geq 70 \%$ from baseline & & & & $100 \%$ & $72 \%$ & $28 \%$ & $0 \%$ & $30 \%$ & $100 \%$ \\
\hline Present & 30 & 9 & 21 & & & & & & \\
\hline Absent & 53 & 0 & 53 & & & & & & \\
\hline Total & 83 & 9 & 74 & & & & & & \\
\hline Delay in onset latency of $\geq 15 \%$ from baseline & & & & $78 \%$ & $96 \%$ & $4 \%$ & $22 \%$ & $70 \%$ & $97 \%$ \\
\hline Present & 10 & 7 & 3 & & & & & & \\
\hline Absent & 73 & 2 & 71 & & & & & & \\
\hline Total & 83 & 9 & 74 & & & & & & \\
\hline Delay in onset latency of $\geq 10 \%$ from baseline & & & & $100 \%$ & $84 \%$ & $16 \%$ & $0 \%$ & $43 \%$ & $100 \%$ \\
\hline Present & 21 & 9 & 12 & & & & & & \\
\hline Absent & 62 & 0 & 62 & & & & & & \\
\hline Total & 83 & 9 & 74 & & & & & & \\
\hline $\begin{array}{l}\text { Decrease in amp of } \geq 70 \% \text { \& delay in onset } \\
\text { latency of } \geq 15 \% \text { from baseline }\end{array}$ & & & & $78 \%$ & $97 \%$ & $3 \%$ & $22 \%$ & $78 \%$ & $97 \%$ \\
\hline Present & 9 & 7 & 2 & & & & & & \\
\hline Absent & 74 & 2 & 72 & & & & & & \\
\hline Total & 83 & 9 & 74 & & & & & & \\
\hline $\begin{array}{l}\text { Decrease in amp of } \geq 70 \% \text { \& delay in onset } \\
\text { latency of } \geq 10 \% \text { from baseline }\end{array}$ & & & & $100 \%$ & $93 \%$ & $7 \%$ & $0 \%$ & $64 \%$ & $100 \%$ \\
\hline Present & 14 & 9 & 5 & & & & & & \\
\hline Absent & 69 & 0 & 69 & & & & & & \\
\hline Total & 83 & 9 & 74 & & & & & & \\
\hline
\end{tabular}

FNR = false negative rate; $F P R=$ false positive rate; $N P V=$ negative predictive value; $P P V=$ positive predictive value; pts = patients.

a specificity of $72 \%$, a false positive rate (FPR) of $28 \%$, a false negative rate (FNR) of $0 \%$, a positive predictive value (PPV) of $30 \%$, and a negative predictive value (NPV) of $100 \%$ for prediction of postoperative motor deficit (Table 2 ). An onset latency delay of $\geq 15 \%$ cutoff gave a sensitivity of $78 \%$, a specificity of $96 \%$, FPR of $4 \%$, FNR of $22 \%$, PPV of $70 \%$, and NPV of $97 \%$, and an onset latency delay of $\geq 10 \%$ cutoff gave a sensitivity of $100 \%$, a specificity of $84 \%$, FPR of $16 \%$, FNR of $0 \%$, PPV of $43 \%$, and NPV of $100 \%$ for prediction of postoperative motor deficit. Combination of a decrease in amplitude of $\geq 70 \%$ and an onset latency of $\geq 15 \%$ from baseline had a sensitivity of $78 \%$, a specificity of $97 \%$, FPR of $3 \%$, FNR of $22 \%$, PPV of $78 \%$, and NPV of $97 \%$, and a combination of a decrease in amplitude of $\geq 70 \%$ and an onset latency of $\geq 10 \%$ from baseline had a sensitivity of $100 \%$, a specificity of $93 \%$, FPR of $7 \%$, FNR of $0 \%$, PPV of $64 \%$, and NPV of $100 \%$ for prediction of postoperative motor deficit. These results showed that a cutoff of an onset latency delay of $\geq 15 \%$ cutoff had decreased sensitivity due to inclusion of 2 falsenegative cases. Therefore, we defined a combination of a decrease in amplitude of $\geq 70 \%$ and an onset latency delay of $\geq 10 \%$ from baseline as the new alarm point (Table 2).

For prediction of postoperative motor deficit, this new alarm point had a sensitivity of $100 \%$, a specificity of $91 \%$, PPV of 50\%, and NPV of $100 \%$ in scoliosis cases $(n=25)$; a sensitivity of $100 \%$, a specificity of $67 \%$, PPV of $50 \%$, and NPV of $100 \%$ in OPLL cases $(\mathrm{n}=16)$; and a sensitivity of $100 \%$, a specificity of $38 \%$, PPV of $44 \%$, and NPV of $100 \%$ in intramedullary tumor cases $(n=12)$ (Table 3$)$. In subgroup analysis in 62 patients who had no preoperative motor deficits (McCormick grade I), the new alarm point of a combination of a decrease in amplitude of $\geq 70 \%$ and an onset latency of $\geq 10 \%$ from baseline had a sensitivity of $100 \%$, a specificity of $90 \%$, FPR of $10 \%$, FNR of $0 \%$, PPV of 33\%, and NPV of $100 \%$ for prediction of postoperative motor deficit (Table 4). There were 5 cases in which the waveform became flat during surgery, including 3 cas-

TABLE 3. Sensitivity, specificity, PPV, and NPV in scoliosis, OPLL, and intramedullary tumor cases based on a decrease in amplitude of $\geq 70 \%$ and delay in onset latency of $\geq 10 \%$ from baseline

\begin{tabular}{lllll}
\hline \multicolumn{1}{c}{ Disease } & Sensitivity & Specificity & PPV & NPV \\
\hline Scoliosis $(\mathrm{n}=25)$ & $100 \%(2 / 2)$ & $91 \%(21 / 23)$ & $50 \%(2 / 4)$ & $100 \%(21 / 21)$ \\
\hline OPLL $(\mathrm{n}=16)$ & $100 \%(4 / 4)$ & $67 \%(8 / 12)$ & $50 \%(4 / 8)$ & $100 \%(8 / 8)$ \\
\hline Intramedullary tumor $(\mathrm{n}=12)$ & $100 \%(4 / 4)$ & $38 \%(3 / 8)$ & $44 \%(4 / 9)$ & $100 \%(3 / 3)$ \\
\hline
\end{tabular}


TABLE 4. Relationship of postoperative motor deficit with waveform amplitude deterioration and delay in onset latency in 62 patients with no motor deficits at baseline

\begin{tabular}{ccrc}
\hline \multirow{2}{*}{$\begin{array}{c}\text { Decrease in Amp of } \geq 70 \% \text { \& Delay in } \\
\text { Onset Latency of } \geq 10 \% \text { From Baseline }\end{array}$} & \multicolumn{3}{c}{ Postop Motor Deficit } \\
\cline { 2 - 4 } & Present & Absent & Total \\
\hline Present & 3 & 6 & 9 \\
\hline Absent & 0 & 53 & 53 \\
\hline Total & 3 & 59 & 62 \\
\hline
\end{tabular}

Sensitivity $=100 \%$, specificity $=90 \%$, false positive rate $=10 \%$, false negative rate $=0 \%$, positive predictive value $=33 \%$, negative predictive value $=100 \%$.

es of thoracic spinal OPLL and 2 cases of intramedullary tumor. In these cases, "onset" was difficult to determine and we were only able to evaluate amplitude alone.

\section{Illustrative Case}

This 13-year-old female patient had a preoperative main Cobb angle of $84^{\circ}$ due to AIS (Fig. 4A). The results of preoperative motor and sensory examinations were normal. The patient underwent posterior spinal fusion with instrumentation from T4 to L4 with posterior osteotomy around the apex of the deformity $(\mathrm{T} 11, \mathrm{~T} 12, \mathrm{~L} 1)$ due to the rigidity of the curve and fused segments (Fig. 4B). She had acceptable baseline $\operatorname{Br}(\mathrm{E})$-MsEP values bilaterally (Fig. $4 \mathrm{C}$, open arrow). After a rotation maneuver, the waveform amplitude deteriorate beyond the $70 \%$ criterion for the adductor longus bilaterally and for the left quadriceps, hamstrings, and gastrocnemius; and onset latency of the gastrocnemius was delayed by $23 \%$ ( $26 \rightarrow 32 \mathrm{msec}$ ) (Fig. 4C). The maneuver was interrupted and the correction was released. The waveform eventually improved to $>50 \%$ of baseline for the left quadriceps, but there was no improvement in the waveforms for the other muscles improved (Fig. 4C). Immediately after surgery, the MMT score in the left quadriceps femoris and hamstrings dropped from the preoperative score of $5 / 5$ to $4 / 5$. The patient's neurological function had normalized at the 1-month postoperative evaluation. The postoperative Cobb angle was $11^{\circ}$, with a curve correction rate of $87 \%$.

\section{Discussion}

The alarm point in intraoperative $\mathrm{Br}(\mathrm{E})-\mathrm{MsEP}$ monitoring has been defined as waveform amplitude disappearance and $\mathrm{a} \geq 50 \%$ D-wave amplitude decrement, ${ }^{31}$ a decrease in amplitude of $\geq 50 \%$ from baseline, ${ }^{27,32,33} \mathrm{a}$ decrease in amplitude of $\geq 70 \%$ from baseline, ${ }^{8,12-14}$ a decrease in amplitude of $\geq 80 \%$ from baseline, ${ }^{16}$ and multiphase of the waveform..$^{27}$ In our facility, we usually use the $70 \%$ amplitude criterion because the monitoring working group of the Japanese Society for Spine Surgery and Related Research recommends this criterion in Japan. ${ }^{8,14}$ However, a clear alarm point for $\mathrm{Br}(\mathrm{E})-\mathrm{MsEP}$ monitoring has yet to be established. Use of an alarm point based only on
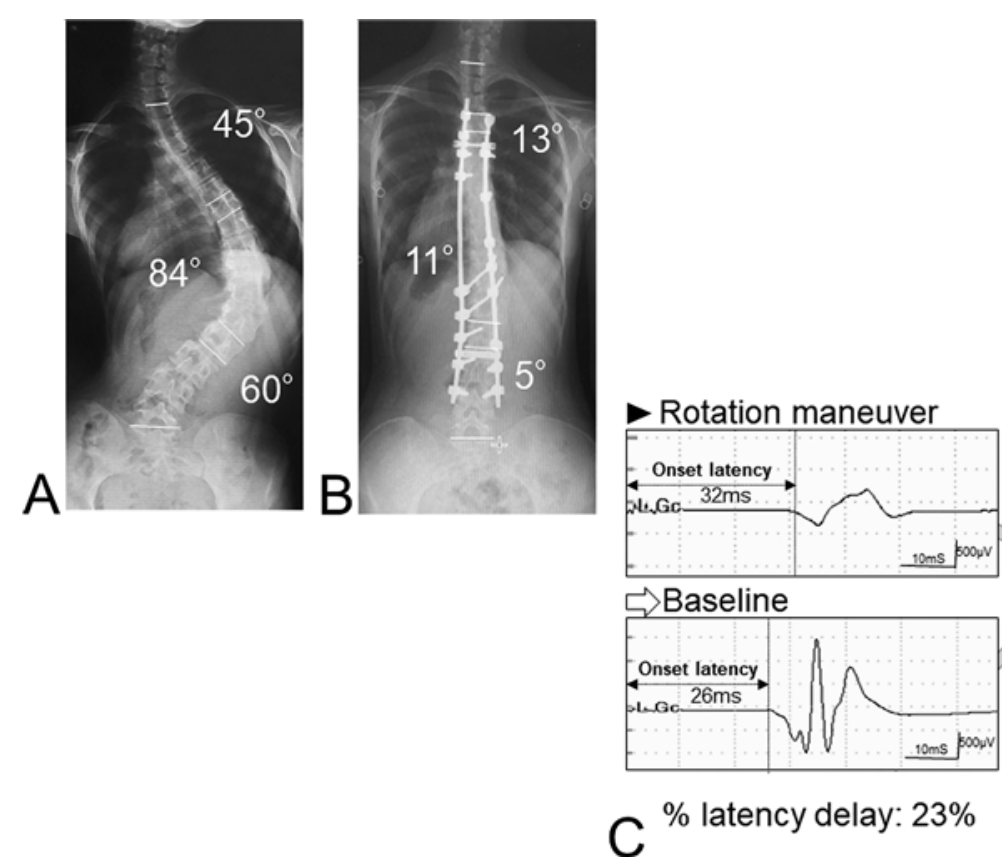

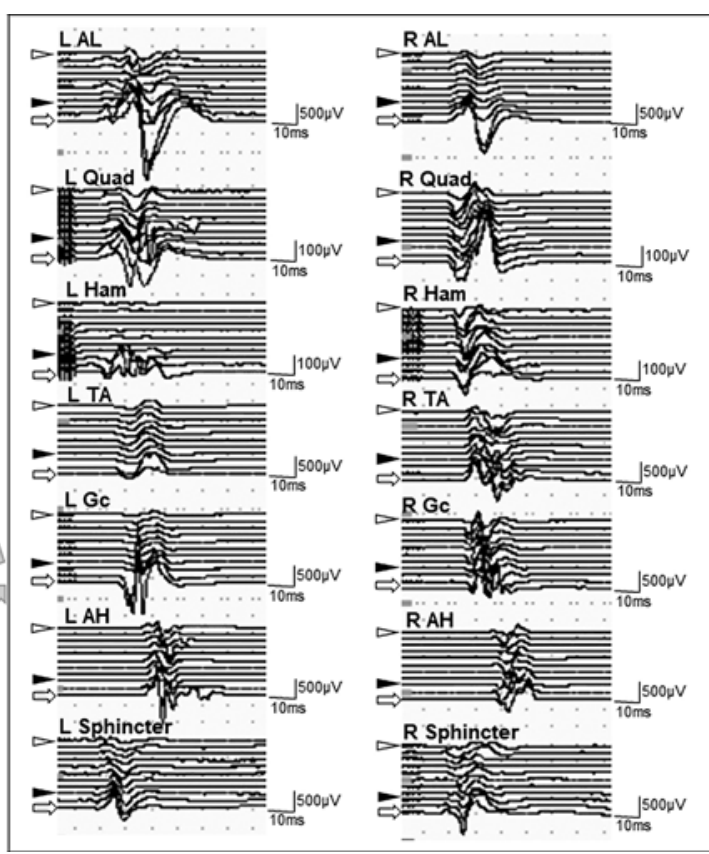

FIG. 4. A: Preoperative posteroanterior radiographs obtained in a 13 -year-old female patient with AIS. The curve magnitudes were $84^{\circ}$ thoracic, $45^{\circ}$ upper thoracic, and $60^{\circ}$ lumbar. B: The patient underwent posterior spinal fusion with instrumentation from T4 to L4 with posterior osteotomy around the apex of the deformity (T11, T12, L1) due to the stiffness of the curve and fused segments. The postoperative Cobb angle was $11^{\circ}$, with a curve correction rate of $87 \%$. C: $\ln \mathrm{Br}(\mathrm{E})$-MsEP monitoring, after a rotation maneuver, the waveform amplitude deteriorated below the $70 \%$ criterion for the adductor longus bilaterally and for the left quadriceps, hamstrings, and gastrocnemius, and the onset latency of the gastrocnemius was delayed by $23 \%$ ( $26 \rightarrow 32 \mathrm{msec}$ ) (arrowhead). The maneuver was interrupted and the correction was released. The waveform eventually improved to $>50 \%$ of baseline for the left quadriceps, while others were not improved (open arrowhead). $\mathrm{AH}=$ abductor hallucis; $\mathrm{AL}=$ adductor longus; $\mathrm{Gc}=$ gastrocnemius; Ham = hamstrings; TA = tibialis anterior. 
$\operatorname{Br}(\mathrm{E})-\mathrm{MsEP}$ amplitude has a concern that the high number of false positives can hamper smooth surgery. ${ }^{8,12-14,23,24}$ Multimodal intraoperative monitoring (MIOM) has been used to attenuate false positives. Sutter and colleagues examined MIOM in 1017 cases, and found a sensitivity of $89 \%$ and a specificity of $99 \%, 32$ and Ito et al. reported that the multimodal approach has a sensitivity of $90 \%$ and a FPR of $6.1 \%{ }^{8}$ However, $63 \%$ of institutions currently use $\mathrm{Br}(\mathrm{E})-\mathrm{MsEP}$ monitoring, and only $27.8 \%$ use $\mathrm{Br}(\mathrm{E})$-SCEP monitoring; and $33 \%$ of facilities use only a single modality. ${ }^{21}$ Thus, it is likely that the number of institutions performing simultaneous MIOM with $\mathrm{Br}(\mathrm{E})$-MsEP and $\mathrm{Br}(\mathrm{E})$-SCEP is relatively low. Therefore, in this situation, it is still important to define a simple alarm point setting.

There are 2 types of criteria for latency: onset and peak. In our series, latency was defined using onset of $\operatorname{Br}(E)-$ MsEP because it is difficult to evaluate the peak at which a waveform change occurs. In contrast, the onset time is easier to determine, and accurate evaluation is possible. Therefore, onset time could be valuable since it is easier to evaluate than peak time. However, when a waveform approaches flatness due to deterioration of the amplitude, it is difficult to determine the onset time point. In these cases, there is no choice but to evaluate amplitude alone, and we included 5 such cases. In our series, according to the ROC analysis, $\geq 15 \%$ might have been a better latency cutoff; however, we examined the data using a $\geq 10 \%$ cutoff (sensitivity $100 \%$, specificity $84 \%$ ) in addition to the $\geq 15 \%$ cutoff (sensitivity $78 \%$, specificity $97 \%$ ). This was because 2 cases with postoperative motor deficit were both false negatives. In surgery, detection of postoperative motor deficit is most important, and therefore, sensitivity is more important and higher sensitivity is required. Therefore, to avoid false-negative cases, we defined the new alarm point using a delay in onset latency of $\geq 10 \%$ from baseline. We note that the 2 false-negatives cases at an onset latency delay of $\geq 15 \%$ cutoff were due to the absolute amplitude being reduced to $\leq 2 \mu \mathrm{V}$. It might not be appropriate to evaluate the alarm point using latency only and might be better to evaluate amplitude and use latency as an auxiliary indicator. Thus, the combination of the high sensitivity of amplitude and high specificity of latency may give an ideal alarm point. Based on this consideration, we finally defined the new alarm point as a combination of a decrease in amplitude of $\geq 70 \%$ and a delay in onset latency of $\geq 10 \%$ from baseline, and this alarm point had $100 \%$ sensitivity, 93\% specificity, FPR 7\%, and FNR 0\%, which is suitable for an alarm point using a single modality.

$\mathrm{Br}(\mathrm{E})$-MsEP monitoring has been performed for various diseases, and detection of root level palsies or brachial plexus compression from positioning has also been reported. Chen et al. ${ }^{5}$ found that multimodality monitoring with spontaneous and electrically triggered EMG combined with SSEP and MEP may be the best approach. Raynor et al. ${ }^{29}$ and Duncan et al. ${ }^{6}$ also reported that, together with SSEP and MEP, EMG is a necessary part of a multimodality protocol for monitoring lumbar spinal nerve roots. In an experimental study, Yang et al. ${ }^{33}$ evaluated the brachial plexus and vessel compression in a combined central and peripheral electrodiagnostic approach. However, the alarm point for detection of root level palsies or brachial plexus compression from positioning has not been determined. Therefore, further studies are needed to determine whether the same parameters can be used for multiple diseases. Based on our findings, it will be necessary to study whether the same parameters apply equally to detection of root level palsies or brachial plexus compression from positioning and to examine new alarm points using amplitude and latency.

In intraoperative spinal cord monitoring, it is important to increase the sensitivity in detection of waveform deterioration. In our series, muscles were monitored routinely through 28 channels in cervical surgery and 18 in thoracic surgery. This is advantageous because the increased number of detection channels allows easy detection of waveform deterioration, which increases the sensitivity. In addition, the combination of amplitude and latency used in this study will make it possible to evaluate intraoperative changes to the spinal cord acutely.

This study has several limitations, including its retrospective design, the small number of cases reducing the power of the statistical analysis, and the variety of surgical procedures. A prospective study would have shown whether cases with new paralysis could have been prevented using the proposed alarm point, and such a should be performed. Within these limitations, we were able to evaluate numerous waveforms from 1726 muscles in 83 cases in detail at a single institution. This is the first study to examine a combination of waveform amplitude and latency as an alarm point and the first to show the efficacy of latency for this purpose. The combination of a decrease in amplitude of $\geq 70 \%$ and a delay in onset latency of $\geq 10 \%$ from baseline gives an alarm point with high specificity that could lead to reduction of false-positive results.

\section{References}

1. Accadbled F, Henry P, de Gauzy JS, Cahuzac JP: Spinal cord monitoring in scoliosis surgery using an epidural electrode. Results of a prospective, consecutive series of 191 cases. Spine (Phila Pa 1976) 31:2614-2623, 2006

2. Bartley K, Woodforth IJ, Stephen JP, Burke D: Corticospinal volleys and compound muscle action potentials produced by repetitive transcranial stimulation during spinal surgery. Clin Neurophysiol 113:78-90, 2002

3. Ben-David B, Haller G, Taylor P: Anterior spinal fusion complicated by paraplegia. A case report of a false-negative somatosensory-evoked potential. Spine (Phila Pa 1976) 12:536-539, 1987

4. Calancie B, Harris W, Broton JG, Alexeeva N, Green BA: "Threshold-level" multipulse transcranial electrical stimulation of motor cortex for intraoperative monitoring of spinal motor tracts: description of method and comparison to somatosensory evoked potential monitoring. J Neurosurg 88:457-470, 1998

5. Chen Y, Wang BP, Yang J, Deng Y: Neurophysiological monitoring of lumbar spinal nerve roots: A case report of postoperative deficit and literature review. Int J Surg Case Rep 30:218-221, 2017

6. Duncan JW, Bailey RA, Baena R: Intraoperative decrease in amplitude of somatosensory-evoked potentials of the lower extremities with interbody fusion cage placement during lumbar fusion surgery. Spine (Phila Pa 1976) 37:E1290-E1295, 2012

7. Gunnarsson T, Krassioukov AV, Sarjeant R, Fehlings MG: Real-time continuous intraoperative electromyographic and 
somatosensory evoked potential recordings in spinal surgery: correlation of clinical and electrophysiologic findings in a prospective, consecutive series of 213 cases. Spine (Phila Pa 1976) 29:677-684, 2004

8. Ito Z, Imagama S, Sakai Y, Katayama Y, Wakao N, Ando K, et al: A new criterion for the alarm point for compound muscle action potentials. J Neurosurg Spine 17:348-356, 2012

9. Jimenez JC, Sani S, Braverman B, Deutsch H, Ratliff JK: Palsies of the fifth cervical nerve root after cervical decompression: prevention using continuous intraoperative electromyography monitoring. J Neurosurg Spine 3:92-97, 2005

10. Jones SJ, Harrison R, Koh KF, Mendoza N, Crockard HA: Motor evoked potential monitoring during spinal surgery: responses of distal limb muscles to transcranial cortical stimulation with pulse trains. Electroencephalogr Clin Neurophysiol 100:375-383, 1996

11. Kobayashi K, Ando K, Yagi H, Ito K, Tsushima M, Morozumi M, et al: Prevention and prediction of postoperative bowel bladder disorder using an anal plug electrode with TcMsEP monitoring during spine surgery. Nagoya J Med Sci 79:459-466, 2017

12. Kobayashi K, Imagama S, Ito Z, Ando K, Hida T, Ishiguro N: Prevention of spinal cord injury using brain-evoked muscleaction potential $(\mathrm{Br}(\mathrm{E})-\mathrm{MsEP})$ monitoring in cervical spinal screw fixation. Eur Spine J 26:1154-1161, 2017

13. Kobayashi K, Imagama S, Ito Z, Ando K, Hida T, Ito K, et al: Transcranial motor evoked potential waveform changes in corrective fusion for adolescent idiopathic scoliosis. J Neurosurg Pediatr 19:108-115, 2017

14. Kobayashi S, Matsuyama Y, Shinomiya K, Kawabata S, Ando M, Kanchiku T, et al: A new alarm point of transcranial electrical stimulation motor evoked potentials for intraoperative spinal cord monitoring: a prospective multicenter study from the Spinal Cord Monitoring Working Group of the Japanese Society for Spine Surgery and Related Research. J Neurosurg Spine 20:102-107, 2014

15. Kothbauer KF, Deletis V, Epstein FJ: Motor-evoked potential monitoring for intramedullary spinal cord tumor surgery: correlation of clinical and neurophysiological data in a series of 100 consecutive procedures. Neurosurg Focus 4(5):e1, 1998

16. Langeloo DD, Journée HL, de Kleuver M, Grotenhuis JA: Criteria for transcranial electrical motor evoked potential monitoring during spinal deformity surgery: a review and discussion of the literature. Neurophysiol Clin 37:431-439, 2007

17. Langeloo DD, Lelivelt A, Louis Journée H, Slappendel R, de Kleuver M: Transcranial electrical motor-evoked potential monitoring during surgery for spinal deformity: a study of 145 patients. Spine (Phila Pa 1976) 28:1043-1050, 2003

18. Lesser RP, Raudzens P, Lüders H, Nuwer MR, Goldie WD, Morris HH III, et al: Postoperative neurological deficits may occur despite unchanged intraoperative somatosensory evoked potentials. Ann Neurol 19:22-25, 1986

19. Luk KD, Hu Y, Wong YW, Cheung KM: Evaluation of various evoked potential techniques for spinal cord monitoring during scoliosis surgery. Spine (Phila Pa 1976) 26:17721777,2001

20. Macdonald DB: Intraoperative motor evoked potential monitoring: overview and update. J Clin Monit Comput 20:347377, 2006

21. Matsuyama Y, Shinomiya K, Ando M, Kazuhiko S, Toshika$\mathrm{zu}$ T, Ishiguro N: [Intraoperative spinal cord monitoringmulti center study of Japanese Society for Spine Surgery and Related Research (JSSR).] Rinsho-Nouha 51:286-291, 2009 (Jpn)

22. McCormick PC, Michelsen WJ, Post KD, Carmel PW, Stein BM: Cavernous malformations of the spinal cord. Neurosurgery 23:459-463, 1988
23. Muramoto A, Imagama S, Ito Z, Ando K, Tauchi R, Matsumoto T, et al: The cutoff amplitude of transcranial motor evoked potentials for transient postoperative motor deficits in intramedullary spinal cord tumor surgery. Spine (Phila Pa 1976) 39:E1086-E1094, 2014

24. Muramoto A, Imagama S, Ito Z, Wakao N, Ando K, Tauchi $\mathrm{R}$, et al: The cutoff amplitude of transcranial motor-evoked potentials for predicting postoperative motor deficits in thoracic spine surgery. Spine (Phila Pa 1976) 38:E21-E27, 2013

25. Paradiso G, Lee GY, Sarjeant R, Hoang L, Massicotte EM, Fehlings MG: Multimodality intraoperative neurophysiologic monitoring findings during surgery for adult tethered cord syndrome: analysis of a series of 44 patients with long-term follow-up. Spine (Phila Pa 1976) 31:2095-2102, 2006

26. Park P, Wang AC, Sangala JR, Kim SM, Hervey-Jumper S, Than KD, et al: Impact of multimodal intraoperative monitoring during correction of symptomatic cervical or cervicothoracic kyphosis. J Neurosurg Spine 14:99-105, 2011

27. Pelosi L, Lamb J, Grevitt M, Mehdian SM, Webb JK, Blumhardt LD: Combined monitoring of motor and somatosensory evoked potentials in orthopaedic spinal surgery. Clin Neurophysiol 113:1082-1091, 2002

28. Quiñones-Hinojosa A, Lyon R, Zada G, Lamborn KR, Gupta $\mathrm{N}$, Parsa AT, et al: Changes in transcranial motor evoked potentials during intramedullary spinal cord tumor resection correlate with postoperative motor function. Neurosurgery 56:982-993, 2005

29. Raynor BL, Lenke LG, Bridwell KH, Taylor BA, Padberg AM: Correlation between low triggered electromyographic thresholds and lumbar pedicle screw malposition: analysis of 4857 screws. Spine (Phila Pa 1976) 32:2673-2678, 2007

30. Sala F, Bricolo A, Faccioli F, Lanteri P, Gerosa M: Surgery for intramedullary spinal cord tumors: the role of intraoperative (neurophysiological) monitoring. Eur Spine J 16 (Suppl 2):S130-S139, 2007

31. Sala F, Palandri G, Basso E, Lanteri P, Deletis V, Faccioli F, et al: Motor evoked potential monitoring improves outcome after surgery for intramedullary spinal cord tumors: a historical control study. Neurosurgery 58:1129-1143, 2006

32. Sutter M, Eggspuehler A, Grob D, Jeszenszky D, Benini A, Porchet F, et al: The diagnostic value of multimodal intraoperative monitoring (MIOM) during spine surgery: a prospective study of 1,017 patients. Eur Spine J 16 (Suppl 2):S162S170, 2007

33. Yang C, Xu J, Chen J, Li S, Cao Y, Zhu Y, et al: Experimental study of brachial plexus and vessel compression: evaluation of combined central and peripheral electrodiagnostic approach. Oncotarget 8:50618-50628, 2017

\section{Disclosures}

The authors report no conflict of interest concerning the materials or methods used in this study or the findings specified in this paper.

\section{Author Contributions}

Conception and design: all authors. Acquisition of data: all authors. Analysis and interpretation of data: Kobayashi, Ando. Drafting the article: Kobayashi. Critically revising the article: Kobayashi. Reviewed submitted version of manuscript: Kobayashi. Statistical analysis: Kobayashi. Administrative/technical/material support: Kobayashi. Study supervision: Imagama.

\section{Correspondence}

Shiro Imagama: Nagoya University Graduate School of Medicine, Aichi, Japan.imagama@med.nagoya-u.ac.jp. 